\title{
Soldagem Unilateral com Suporte Cerâmico de Cordierita
}

\author{
(One-Sided Welding with Cordierite Ceramic Backing)
}

\begin{abstract}
Luciana Lezira Pereira de Almeida ${ }^{1}$, Luiz Cláudio Soares Tatagiba ${ }^{1}$, Ruben Rosenthal ${ }^{1}$, Ronaldo Pinheiro da Rocha Paranhos ${ }^{1}$
${ }^{1}$ LAMAV-CCT - UENF. Campos dos Goytacazes - Rio de Janeiro - Brasil. paranhos@ uenf.br
\end{abstract}

\begin{abstract}
Resumo
Este trabalho apresenta a avaliação de juntas soldadas com suporte cerâmico de cordierita produzido em laboratorio. Foi utilizada a técnica de soldagem unilateral em chapas de aço A-36 com espessuras de 6,4 e 15,8 mm pelo processo MIG-MAG. Com a chapa de 6,4 mm foi avalliado apenas o passe de raiz sobre o suporte cerâmico. Com a chapa de 15,8 mm foi produzida uma junta soldada em passes múltiplos. Após soldagem as juntas soldadas foram submetidas a ensaios de inspeção visual, liquido penetrante, macrografia, microdureza Vickers, microscopia ótica, ensaios de dobramento e de tração e análise química por EDS. Os resultados mostram que o passe de raiz, realizado sobre o suporte cerâmico, apresentou bom acabamento, isento de descontinuidades, com penetração adequada nas laterais do chanfro e reforço de solda apropriado. Em relação à junta soldada, a microestrutura da zona fundida (ZF) obteve predominância de ferrita primária, em suas formas de ferrita de contorno de grão e poligonal, e ferrita com segunda fase alinhada. A microdureza Vickers obteve valores médios abaixo de $180 \mathrm{HV}$ tanto na zona termicamente afetada (ZTA) como na ZF. Os ensaios de dobramento não apresentaram descontinuidades maiores que 3 mm e nos ensaios de tração a ruptura ocorreu no metal base, indicando que o procedimento de soldagem foi adequado. A composição das inclusões tanto do passe de raiz como do ultimo passe de solda possuem os mesmos constituintes, apesar de proporções diferentes, indicando que não houve contaminação do material do suporte cerâmico no cordão de solda.
\end{abstract}

Palavras-chave: Soldagem unilateral, Suporte cerâmico.

Abstract: This work presents the evaluation of welded joints using ceramic backing made in the laboratory. The one-sided welding technique was used to weld A-36 steel plate with 6,4 and 15,8 mm thick by the GMAW process. With the 6,4 mm steel plate, only the root bead welded over the ceramic backing was evaluated. With the 15,8 $\mathrm{mm}$ steel plate, a multipass welded joint was made. After welding, the welded joints were submitted to visual inspection, dye penetrant, macrograph, Vickers micro hardness, optical microscopy, bending and tensile testing and chemical analysis by EDS. The results show that the root pass made over the ceramic backing, presented adequate good shape, free from discontinuities, with adequate penetration in the edges of the groove and adequate reinforcement. Concerning the welded joint, the microstructure of the fusion zone presented predominance of primary ferrite, consisting of grain boundary ferrite and polygonal ferrite, and ferrite with aligned second phase. The Vickers micro hardness obtained mean values below 180 HV both in the heat affected zone and the fusion zone. Bending tests did not show discontinuities greater than $3 \mathrm{~mm}$ and in the tensile tests the rupture occurred in the base metal, indicating that the welding procedure was adequate. The chemical composition of the inclusions both in the root pass as in the last weld bead have the same constituents, despite different proportions, indicating that there was not contamination of the ceramic backing material into the weld bead.

Key words: one-side welding, ceramic backing.

\section{Introdução}

A soldagem unilateral é utilizada tipicamente em aplicações que envolvem acesso apenas por um lado da peça, ou em situações em que a peça não pode ser virada. Obtém penetração total do primeiro passe de solda, evitando-se a subseqüente operação de goivagem para a soldagem no lado oposto da peça [1]. Outras vantagens atribuídas à soldagem unilateral

(Recebido em 23/10/2009; Texto final em 30/03/2010). são: redução dos ensaios não destrutivos (END) e dos reparos; diminuição significativa de defeitos como falta de fusão e redução na distorção dos equipamentos após soldagem [2].

Entre os diversos tipos de suporte de solda usados na soldagem unilateral, é dedicada atenção neste trabalho ao suporte cerâmico, que tem a capacidade de tolerar a elevada temperatura da poça de solda quando no estado líquido, evitar a formação de gases durante a soldagem e proporcionar um acabamento adequado do cordão de solda, isento de defeitos [3].

$\mathrm{O}$ uso do suporte cerâmico em operações de soldagem apresenta um forte impacto tecnológico, pois reduz o número de passes de solda, reduz o volume do metal depositado, elevando a produtividade e reduzindo os custos da operação de soldagem [4]. 

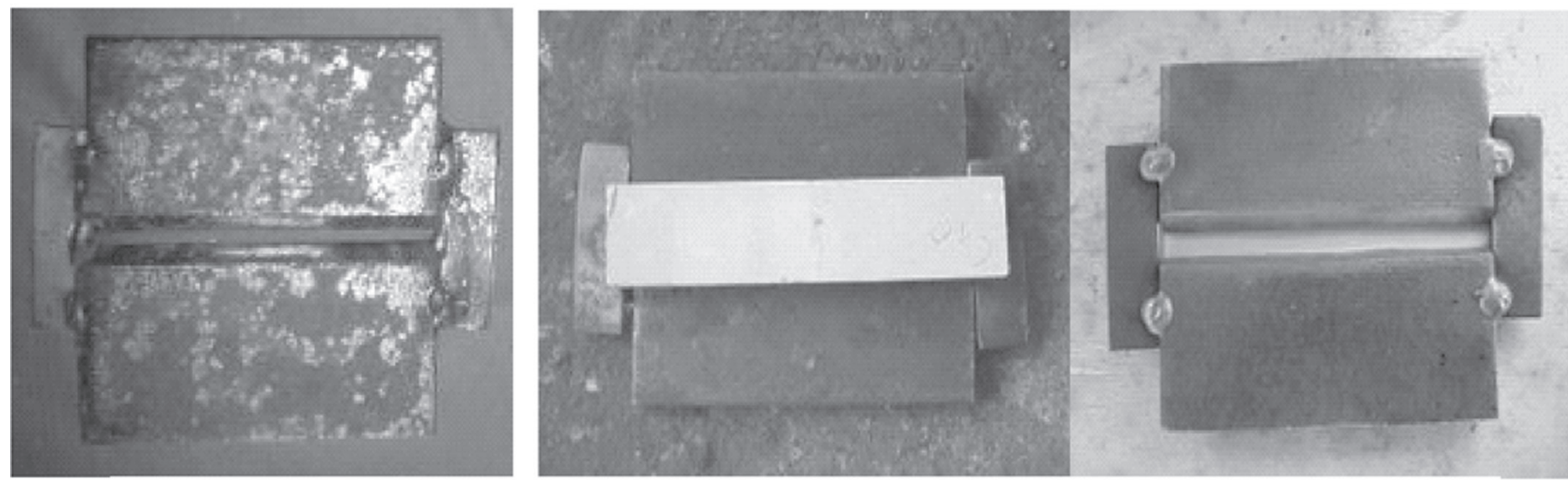

Figura 1 - Preparação do suporte cerâmico na junta (a) chapa de teste, (b) parte inferior da chapa com o suporte cerâmico e (c) parte superior da chapa com o suporte cerâmico fixado na parte de baixo

O objetivo deste trabalho é avaliar as características operacionais, propriedades e microestrutura do passe de raiz e da junta soldada com vários passes de solda, usando o processo MIG-MAG e usando um suporte cerâmico produzido em laboratório. Este é constituído do material refratário cordierita, com aglomerante silicato de sódio e sinterizado a $1100{ }^{\circ} \mathrm{C}$. Detalhes das características de fabricação do suporte cerâmico podem ser obtidos em trabalhos já publicados $[5,6]$.

\section{Materiais e Métodos}

Os materiais utilizados neste trabalho foram: suporte cerâmico a base de material refratário cordierita desenvolvido no LAMAV/UENF [5,6]; chapa de aço carbono A36 com espessuras de 6,4 e 15,8 mm; processo de soldagem MIG-MAG semi-automático na posição plana, com arame ER70S-6 de diâmetro $0,8 \mathrm{~mm}$ e gás de proteção uma mistura $75 \%$ Ar e $25 \%$ $\mathrm{CO}_{2}$ com vazão de $13 \mathrm{l} / \mathrm{min}$. Na soldagem do passe de raiz houve uma pequena oscilação lateral da tocha. Nos demais passes de solda foi usada a técnica de cordão retilíneo.

Numa primeira etapa, foi estudada apenas a soldagem do passe de raiz sobre o suporte cerâmico. A figura 1a mostra a montagem do suporte cerâmico na junta da chapa de aço, com dimensões de $122 \times 101 \times 6,4 \mathrm{~mm}$ com chanfro em V, ângulo de $45^{\circ}$ e abertura de raiz de $2 \mathrm{~mm}$. Apêndices foram soldados nas extremidades da chapa com o objetivo de iniciar e terminar a solda fora da chapa de teste, assim como manter constante a abertura de raiz. A figura $1 \mathrm{~b}$ mostra o suporte cerâmico montado na parte inferior da chapa, que foi fixado por meio de uma fita crepe. A figura 1c mostra a chapa preparada para soldagem, com o suporte cerâmico fixado e posicionado adequadamente sob a junta a ser soldada. A tabela 1 mostra os parâmetros de solda utilizados. Após a soldagem, os corpos de prova foram submetidos a inspeção visual e líquido penetrante para avaliar a qualidade da raiz no que diz respeito a descontinuidades superficiais. Uma macrografia da seção transversal foi preparada e atacada com NITAL $10 \%$.

$\mathrm{O}$ perfil de microdureza Vickers com uma carga de $100 \mathrm{~g}$ foi obtido no microdurômetro modelo HMV-2, do fabricante Shimadzu do Brasil. Foram realizadas 18 medições de microdureza, sendo 6 medidas para o metal base, 6 medidas para a ZTA e 6 medidas para o metal de solda, como mostra a figura 2. Todas as medidas foram feitas sob uma linha horizontal ao longo da extensão do passe de raiz, a uma distância de $1,5 \mathrm{~mm}$ da parte inferior da chapa.

Tabela 1 - Parâmetros da soldagem nos corpos de prova com espessura de $6,4 \mathrm{~mm}$

\begin{tabular}{|c|c|c|c|}
\hline Experimento & $\begin{array}{c}\text { Tensão } \\
(\mathrm{V})\end{array}$ & $\begin{array}{c}\text { Corrente } \\
(\mathrm{A})\end{array}$ & $\begin{array}{c}\text { Velocidade de } \\
\text { Soldagem }(\mathrm{mm} / \mathrm{s})\end{array}$ \\
\hline C1 & $20-22$ & 140 & 2,08 \\
\hline C2 & $20-22$ & 155 & 1,75 \\
\hline C3 & $20-22$ & 140 & 1,92 \\
\hline C4 & $20-22$ & 155 & 2,22 \\
\hline C5 & $20-22$ & 140 & 2,00 \\
\hline C6 & $20-22$ & 140 & 2,04 \\
\hline C7 & $20-22$ & 156 & 2,13 \\
\hline C8 & $20-22$ & 140 & 1,72 \\
\hline C9 & $20-22$ & 150 & 2,17 \\
\hline C10 & $20-22$ & 140 & 2,22 \\
\hline C11 & $20-22$ & 140 & 1,88 \\
\hline C12 & $20-22$ & 110 & 1,88 \\
\hline
\end{tabular}

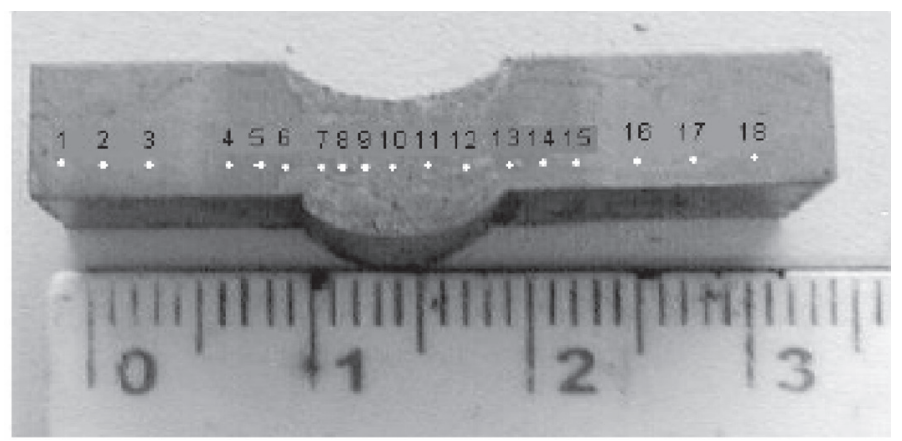

Figura 2 - Pontos que foram calculados a microdureza Vickers da junta soldada com apenas um passe de solda

$\mathrm{Na}$ segunda etapa, foi preparada uma junta soldada em chapa de aço carbono A-36 com dimensões 500 x 300 x 15,8 $\mathrm{mm}$ com chanfro em $\mathrm{V}$, ângulo de $60^{\circ}$ e abertura de raiz de $3 \mathrm{~mm}$ 


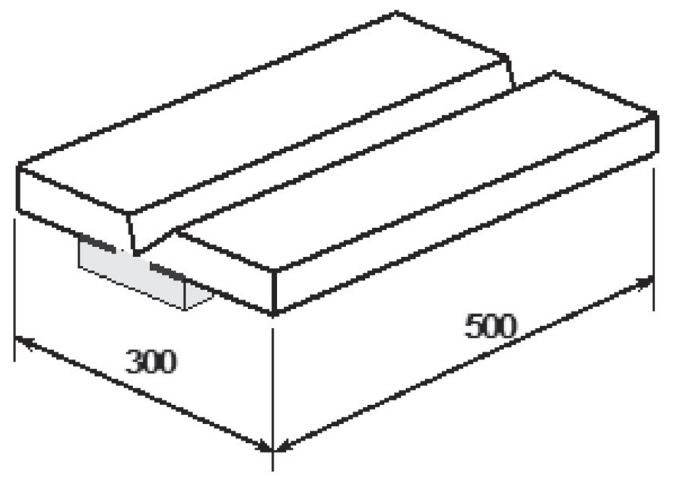

(a)

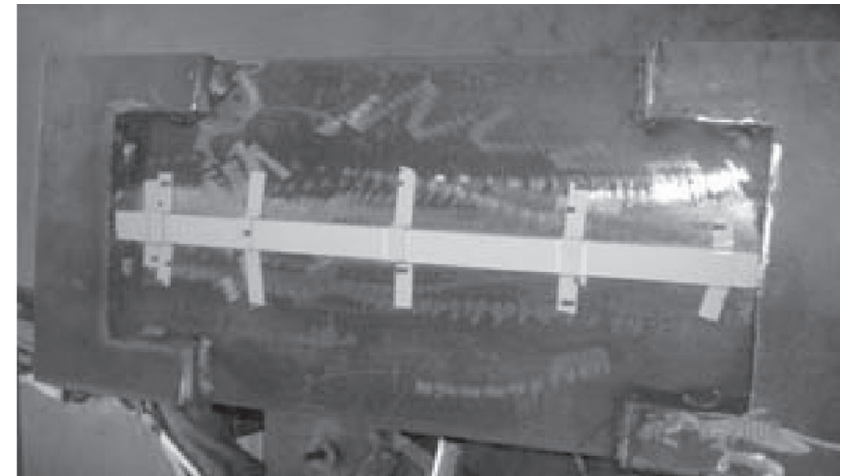

(b)

Figura 3 - (a) Desenho esquemático com dimensões da chapa de teste e (b) Montagem do suporte cerâmico na parte inferior da chapa de aço antes da soldagem

como mostra a figura 3. Dispositivos auxiliares de montagem foram usados para que durante a soldagem a abertura de raiz permanecesse constante, assim como minimizar as distorções causadas pela soldagem. Os suportes cerâmicos foram montados alinhados sob a base inferior do chanfro e fixados com fita crepe, como indicado na figura $3 \mathrm{~b}$. Os parâmetros de soldagem medidos durante a soldagem multipasse são mostrados na tabela 2.

Tabela 2 - Parâmetros de soldagem medidos durante a execução da solda

\begin{tabular}{|c|c|c|c|}
\hline Passe & Tensão (V) & Corrente (A) & $\begin{array}{c}\text { Tempo de arco } \\
\text { aberto (min) }\end{array}$ \\
\hline 01 & 20 a 22 & 135 a 141 & 3,25 \\
\hline 02 & 20 a 22 & 147 a 148 & 3,77 \\
\hline 03 & 20 a 22 & 138 a 147 & 4,17 \\
\hline 04 & 20 a 22 & 135 a 148 & 4,12 \\
\hline 05 & 20 a 22 & 144 a 160 & 1,77 \\
\hline 06 & 20 a 22 & 143 a 156 & 1,52 \\
\hline
\end{tabular}

Após a soldagem do corpo de prova, foram realizados ensaios não destrutivos de inspeção visual e líquido penetrante para avaliar a qualidade da solda no que diz respeito a defeitos superficiais. Uma macrografia da seção transversal foi preparada e atacada com Nital $10 \%$.

O perfil de microdureza Vickers com uma carga de 100 g foi obtido com 18 medições na parte inferior da chapa e 18 medições na parte superior da chapa, como mostra a figura 4 , sendo 6 medidas para o metal base, 6 medidas para a ZTA e 6 medidas para o metal de solda. Todas as medidas foram feitas sob uma linha horizontal a uma distância de $1,5 \mathrm{~mm}$ da parte inferior e superior da chapa.

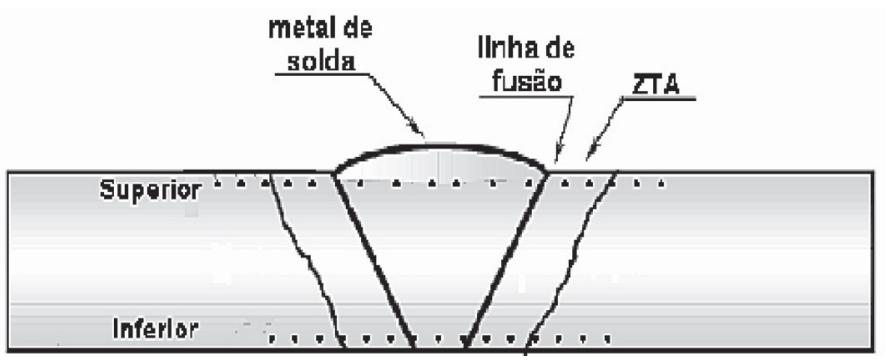

Figura 4 Pontos onde foram realizadas as medidas de microdureza Vickers
Quatro corpos de prova de dobramento lateral e dois corpos de prova de tração transversal foram preparados conforme a norma ASME IX. A figura 5 mostra a posição e a quantidade de corpos de prova retirados da chapa soldada para a realização dos ensaios de tração e dobramento. Os ensaios de dobramento servem para se avaliar a ductilidade da junta soldada, bem como detectar pequenas descontinuidades, pois estas tendem a se propagar durante o ensaio. Os ensaios de tração tiveram como objetivo determinar a resistência à tração e o local de ruptura dos corpos de prova.

A microestrutura da junta soldada foi avaliada por metalografia ótica, sendo utilizado o ataque químico NITAL $2 \%$, que permitiu observar a distribuição das diversas estruturas formadas no passe de raiz e no ultimo passe de solda.

No passe de raiz e no passe de acabamento foi feita uma a análise química das inclusões com auxílio de um EDS acoplado ao MEV SSX-550, da empresa SHIMADZU, com o objetivo de identificar se houve contaminação do material refratário do suporte cerâmico no metal de solda.

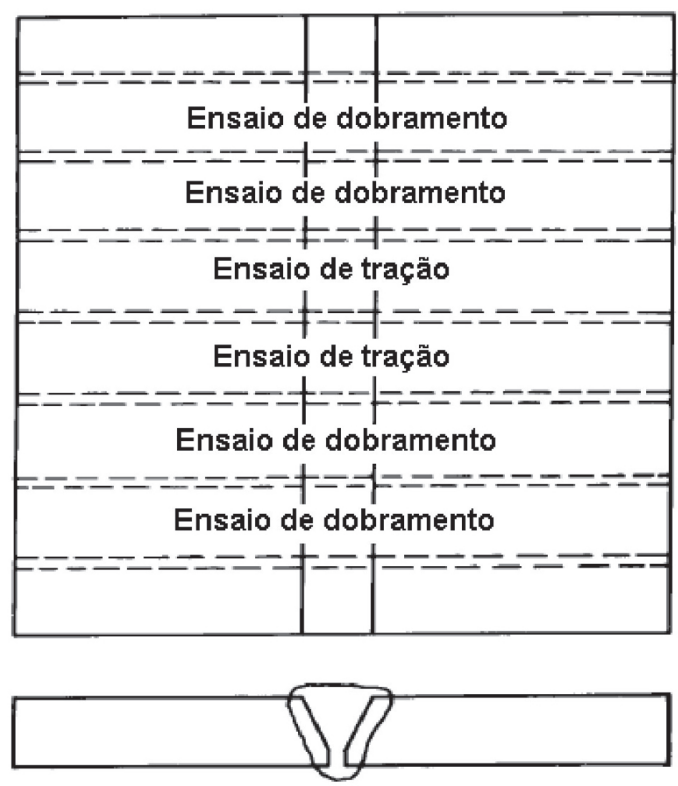

Figura 5 Localização dos corpos de prova para os ensaios de tração e dobramento 


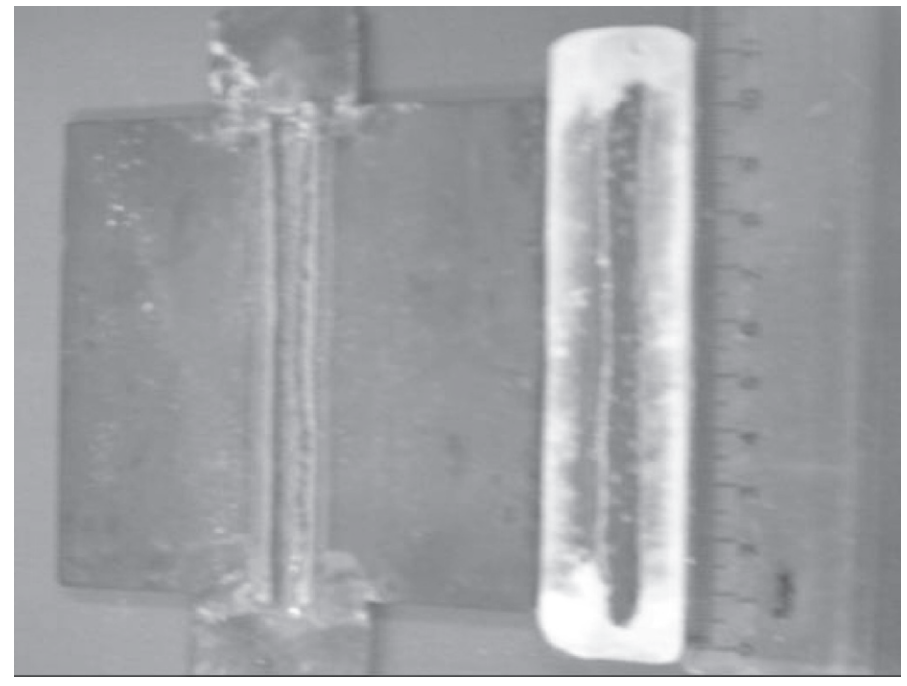

(a)

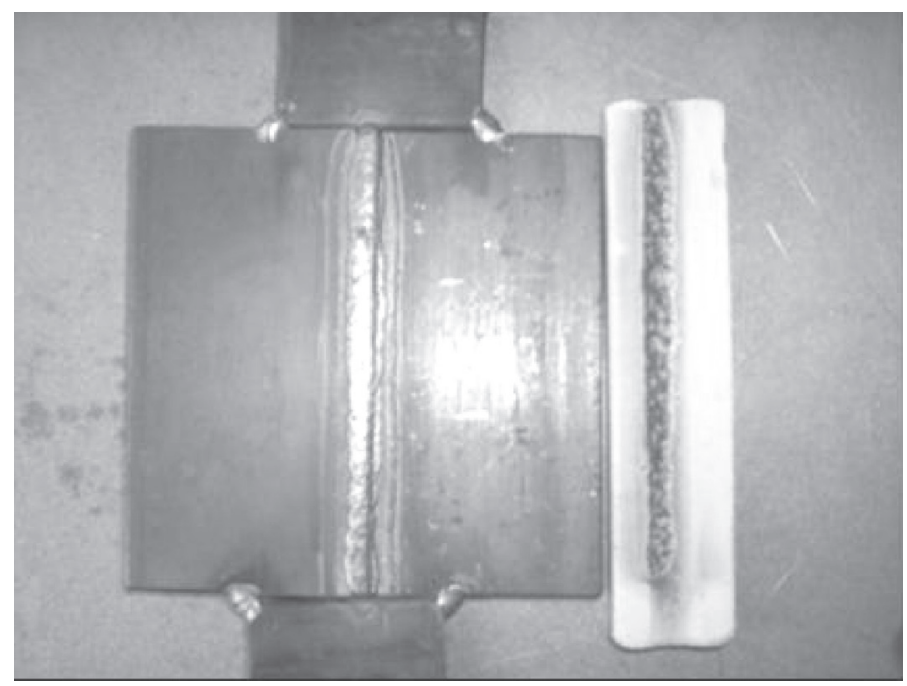

(c)

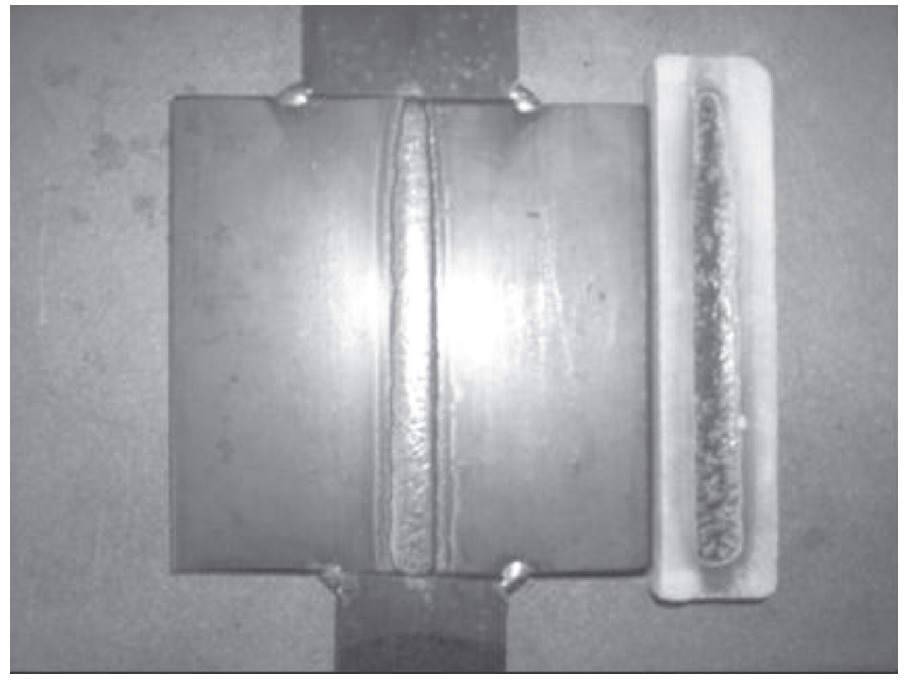

(b)

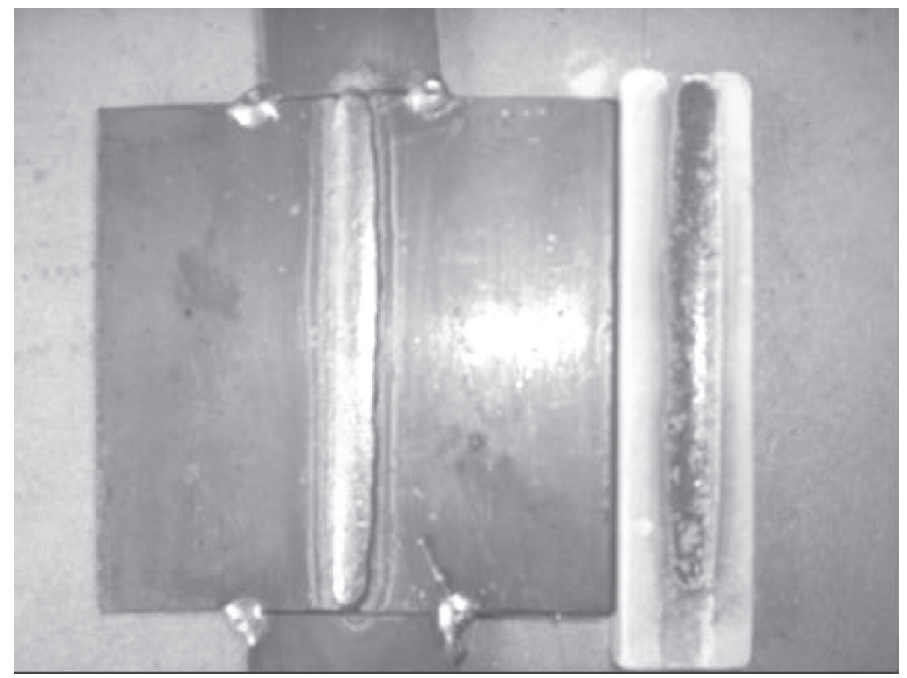

(d)

Figura 6 Corpos de prova após soldagem: (a) C1, (b) C3, (c) C6 e (d) C8

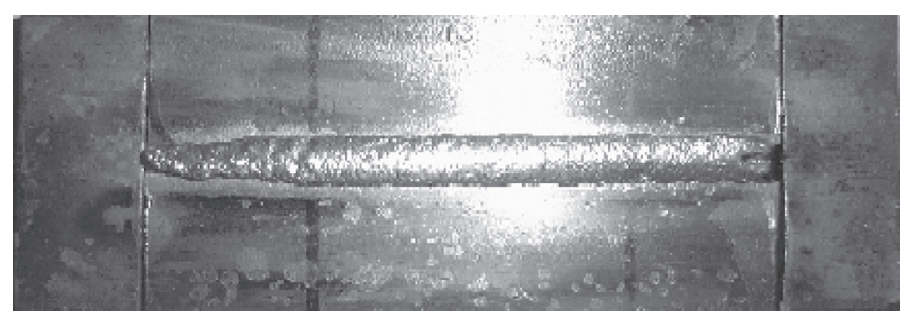

(a)

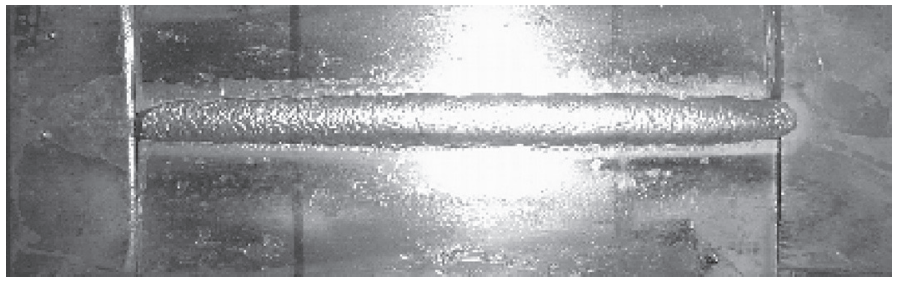

(b)

Figura 7 Inspeção visual dos corpos de provas: (a) C1, (b) C2

\section{Resultados e Discussão}

A primeira etapa deste trabalho teve como objetivo avaliar os parâmetros de soldagem adequados, a qualidade do passe de raiz e a eficiência do suporte cerâmico de cordierita produzido em laboratório em suportar a poça de solda líquida. A figura
6 apresenta alguns corpos de prova após a soldagem. Pode ser observado que o suporte cerâmico resistiu ao elevado aporte de calor durante a soldagem, fundindo-se localmente, protegendo o metal de solda líquido e oferecendo um adequado acabamento ao cordão de solda.

A inspeção visual da raiz dos cordões de solda, ou seja, da 


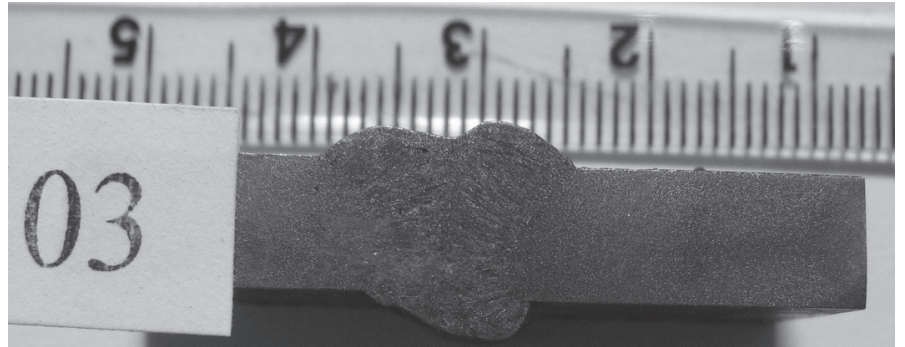

(a)

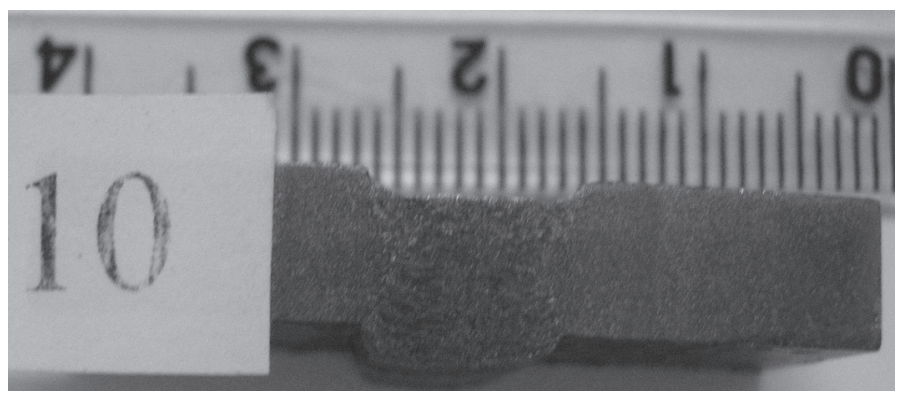

(c)

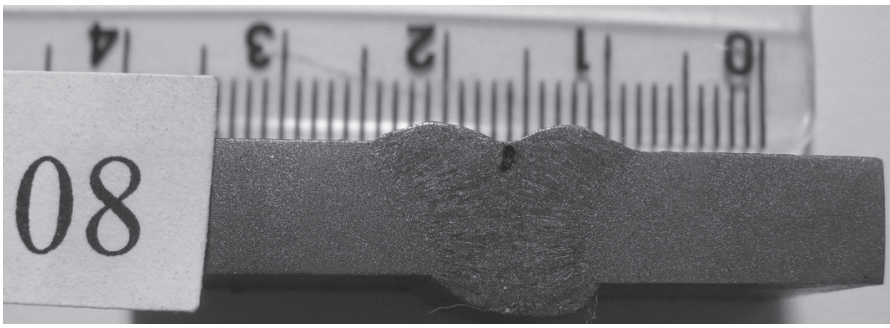

(b)

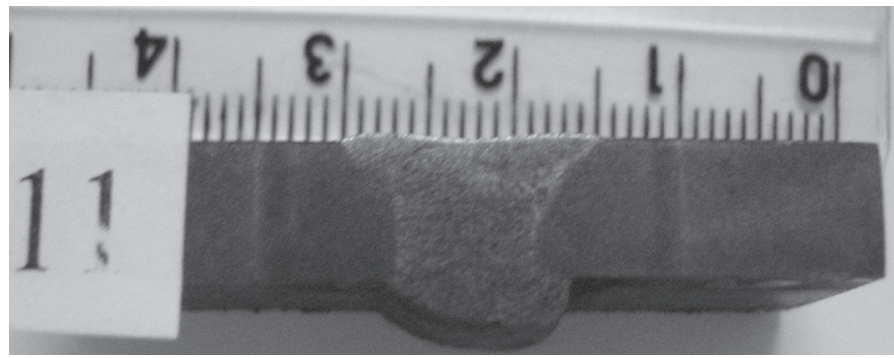

(d)

Figura 8 Macrografia; corpos de prova (a) C3, (b) C8, (c) C10 e (d) C11

Tabela 3 - Valores da microdureza da junta soldada com apenas um único passe

\begin{tabular}{|c|c|c|c|c|c|}
\hline \multirow{2}{*}{ Região } & Pontos & $\begin{array}{c}\text { Microdureza Vickers } \\
\left(\mathrm{kgf} / \mathrm{mm}^{2}\right)\end{array}$ & Pontos & $\begin{array}{c}\text { Microdureza Vickers } \\
\left(\mathrm{kgf} / \mathrm{mm}^{2}\right)\end{array}$ & $\begin{array}{c}\text { Média de Microdureza } \\
\text { e Erro Absoluto }\end{array}$ \\
\hline \multirow{3}{*}{ Metal Base } & 1 & 147 & 16 & 149 & \multirow{2}{*}{$147 \pm 8$} \\
\cline { 2 - 5 } & 2 & 140 & 17 & 147 & \\
\cline { 2 - 5 } & 3 & 153 & 18 & 147 & \multirow{2}{*}{$149 \pm 27$} \\
\cline { 2 - 5 } ZTA & 5 & 134 & 14 & 160 & \\
\cline { 2 - 5 } Metal de & 6 & 134 & 15 & 147 & \multirow{2}{*}{$143 \pm 10$} \\
\cline { 2 - 5 } Solda & 7 & 153 & 11 & 140 & 134 \\
\cline { 2 - 5 } & 9 & 147 & 14 & 147 & \\
\hline
\end{tabular}

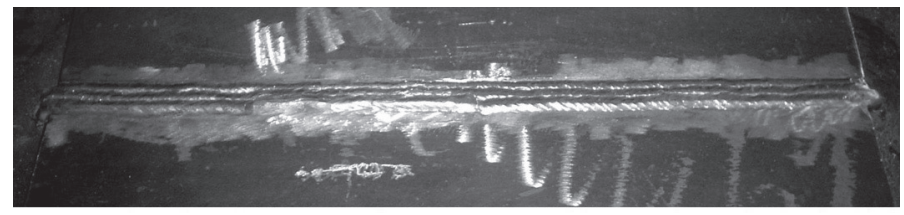

(a)

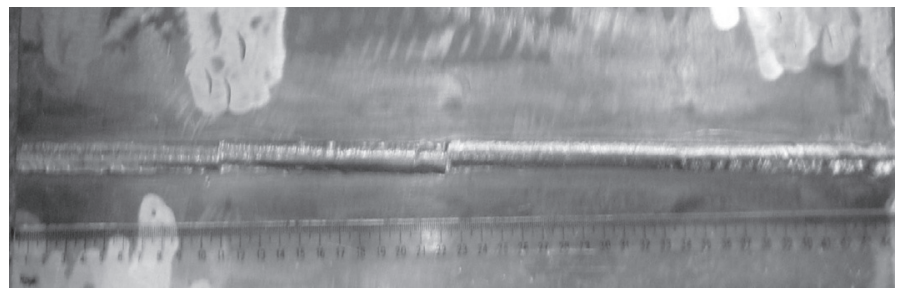

(b)

Figura 9 Resultado da Inspeção visual do cordão de solda (a) acabamento e (b) raiz da solda

superfície que esteve em contato com o suporte cerâmico de cordierita, figura 7, mostra o aspecto e o acabamento do cordão de solda, que foram considerados como adequados e isentos de descontinuidades superficiais. O ensaio por líquido penetrante também não revelou descontinuidades, sendo todas as soldas consideradas como adequadas.

A figura 8 apresenta macrografias da seção transversal do passe de raiz obtido utilizando suportes de solda de cordierita na chapa de aço com 6,4 mm . Observa-se que em todos os corpos de prova obteve-se penetração nas laterais do chanfro.
Apenas o corpo de prova C8, na figura 8(b), apresentou um pequeno poro próximo à parte superior do cordão de solda. Esta descontinuidade observada não foi considerada crítica à qualidade do cordão de solda, sendo associada ao processo de soldagem MIG-MAG. Nos demais corpos de prova não foram observados descontinuidades. Nota-se que na parte superior da solda do corpo de prova C10, figura 8(c), não houve enchimento suficiente da junta soldada, ou seja, de toda a espessura da chapa. De fato, o objetivo desta etapa é de avaliar o primeiro cordão de solda (passe de raiz) produzido com o uso do suporte cerâmico. 
No caso de uma junta soldada, haveria a necessidade de aplicar cordões de solda adicionais sobre este passe de raiz, com o objetivo de encher a junta. Os resultados aqui obtidos estão de acordo com Andrade [7], que apresentou a viabilidade técnica da soldagem do passe de raiz com suporte cerâmico e processo de soldagem por arame tubular robotizado, estabelecendo os parâmetros de soldagem de corrente de $205 \mathrm{~A}$, tensão de $26 \mathrm{~V}$ e velocidade de soldagem de $20 \mathrm{~cm} / \mathrm{min}$, usando abertura da face de raiz de $3 \mathrm{~mm}$, ângulo de chanfro de $40^{\circ}$ e $60^{\circ}$ e ângulo de inclinação da tocha de $15^{\circ}$.

A tabela 3 mostra os valores de microdureza das três regiões da solda do corpo de prova $\mathrm{C} 12$, conforme figura 2. O metal base apresentou valores de dureza entre 140 a $153 \mathrm{kgf} / \mathrm{mm}^{2}$, a ZTA apresentou valores entre 134 a $168 \mathrm{kgf} / \mathrm{mm}^{2}$ e o metal de solda valores entre 134 a $147 \mathrm{kgf} / \mathrm{mm}^{2}$. Estes valores indicam que não houve a formação de fases duras tanto no passe de raiz como na ZTA.

Em relação a segunda etapa do trabalho, esta teve como objetivo avaliar uma junta soldada com a técnica de soldagem unilateral. A figura 9 apresenta o aspecto do cordão de solda sendo (a) parte superior e (b) raiz da solda. A inspeção visual e por líquido penetrante não detectaram descontinuidades superficiais e também não foi observada adesão de material cerâmico no cordão de solda.

A macrografia da seção transversal da junta soldada chapa de aço A36 com espessura de 15,8 mm utilizando o suporte cerâmico de cordierita é mostrada na figura 10. É possível observar as regiões de 1 a 6 , que mostram cada um dos cordões de solda depositados, a região 7 ilustra a ZTA e a região 8 ilustra o metal base. Observa-se que houve penetração nas laterais do chanfro e reforço de solda apropriado, tanto na raiz como nos cordões de acabamento.

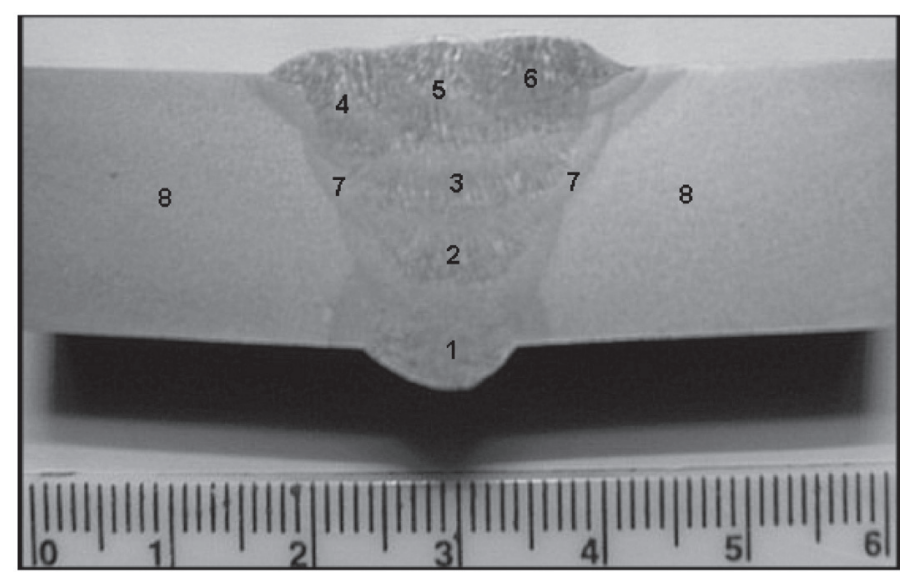

Figura 10 Macrografia da junta soldada com vários passes

A tabela 4 apresenta os resultados de microdureza Vickers desta junta soldada com vários passes. Em relação ao metal base tanto a parte inferior e superior da junta soldada apresentaram valores de dureza entre 137 a $186 \mathrm{HV}$, compatível com o aço A-36. Nota-se ainda que os valores médios da parte superior e inferior do metal base são próximos, o que era esperado. Em relação a ZTA, foram observados valores de microdureza entre 140 a $186 \mathrm{HV}$, mostrando que o ciclo térmico da soldagem não produziu um endurecimento significativo nesta região. Em relação ao metal de solda, foram observados valores entre 138 a $184 \mathrm{HV}$, compatível ao metal de adição produzido com o arame ER70S-6 utilizado na soldagem MIG-MAG. A tabela 4 mostra que tanto a ZTA como o metal de solda apresentaram na parte superior da junta (acabamento da solda) valores de microdureza ligeiramente acima que na parte inferior da junta (raiz da solda). Este fato é atribuido aos efeitos dos ciclos térmicos que ocorrem na raiz da solda com a deposição dos passes subsequentes.

Os resultados do ensaio de microdureza Vickers não apresentaram diferenças significativas entre a soldagem de apenas o passe de raiz (veja tabela 3) e na junta soldada com vários passes (tabela 4), mostrando que a técnica de soldagem unilateral com suporte cerâmico de cordierita por sí só não compromete a dureza da junta soldada.

A figura 11(a) apresenta os 4 corpos de prova após o ensaio de dobramento. Não foram observadas indicações de descontinuidades maiores que $3,0 \mathrm{~mm}$, que é o critério de aceitação previsto na seção IX do Código ASME. Todos os corpos de prova foram considerados aprovados.

A figura 11(b) mostra os corpos de prova do ensaio de tração após o ensaio, podendo ser observado que estes romperam no metal base, em regiões distantes da solda. Os valores da resistência à tração são mostrados na tabela 5. Comparando com os valores especificados para o aço A-36, pode-se concluir que a resistência à tração encontra-se dentro da faixa determinada para este tipo de aço. Estes resultados indicam que o procedimento de soldagem adotado com o uso de suporte cerâmico de cordierita foi correto e que tanto a zona fundida quanto a ZTA apresentam ductilidade e resistência mecânica compatíveis com o metal base.

As figura 12 mostra a microestrutura do passe de raiz da junta soldada com vários passes. Pode ser observado uma quantidade significativa de ferrita com segunda fase alinhada $(\mathrm{FS}(\mathrm{A}))$ e ferrita de contorno de grão $(\mathrm{PF}(\mathrm{G}))$, e alguma ferrita acicular (AF). Nesta análise qualitativa não foi verificada a presença de martensita (M) nem de agregado ferrita-carbeto (FC). A microestrutura obtida é típica do metal de solda de aços ferriticos baixo carbono e compativel com os valores de dureza observados.

A figura 13 apresenta a microestrutura do último passe de solda. Pode-se observar uma microestrutura parecida com a observada no passe de raiz. Estas estruturas são típicas dos cordões de solda realizados com o processo MIG-MAG com arame ER70S-6.

As inclusões presentes no passe de raiz, do tipo globular, aparecem em grande número, como mostrado por técnica de microscopia ótica sem ataque na figura 14 . O mesmo foi observado no cordão de solda de acabamento. Os espectros de EDS acoplado ao MEV das inclusões não metálicas tanto do passe de raíz como do passe de acabamento são mostrados nas figuras 15 e 16 . No ultimo passe de solda a composição típica das inclusões foi cerca de $57 \% \mathrm{Fe}, 11 \% \mathrm{Al}, 26 \% \mathrm{O}_{2}$ com alguns picos de $\mathrm{C}, \mathrm{Mg}$ e $\mathrm{Si}$. No passe de raiz, que esteve em contato com o suporte cerâmico de cordierita a composição foi de cerca de $37 \%$ O2, 31\% Fe, 20\% Al, com alguns picos de Si e C.

Os EDS das figuras 15 e 16 mostram que a composição das inclusões tanto do passe de raiz como do ultimo passe de 
Tabela 4 - Valores da microdureza HV100g da junta soldada

\begin{tabular}{|c|c|c|c|c|c|}
\hline Região & Pontos & $\begin{array}{c}\text { Microdureza } \\
\text { Vickers }\left(\mathrm{kgf} / \mathrm{mm}^{2}\right)\end{array}$ & Pontos & $\begin{array}{c}\text { Microdureza } \\
\text { Vickers }\left(\mathrm{kgf} / \mathrm{mm}^{2}\right)\end{array}$ & $\begin{array}{l}\text { Média de Microdureza e erro } \\
\text { absoluto }\end{array}$ \\
\hline \multirow{3}{*}{$\begin{array}{l}\text { Metal Base } \\
\text { (superior) }\end{array}$} & 1 & 173 & 16 & 173 & \multirow{3}{*}{$173 \pm 14$} \\
\hline & 2 & 165 & 17 & 168 & \\
\hline & 3 & 174 & 18 & 186 & \\
\hline \multirow{3}{*}{$\begin{array}{l}\text { Metal Base } \\
\text { (Inferior) }\end{array}$} & 1 & 166 & 16 & 137 & \multirow{3}{*}{$152 \pm 20$} \\
\hline & 2 & 154 & 17 & 145 & \\
\hline & 3 & 159 & 18 & 151 & \\
\hline \multirow{3}{*}{$\begin{array}{c}\text { ZTA } \\
\text { (Superior) }\end{array}$} & 4 & 140 & 13 & 185 & \multirow{3}{*}{$173 \pm 33$} \\
\hline & 5 & 177 & 14 & 176 & \\
\hline & 6 & 177 & 15 & 186 & \\
\hline \multirow{3}{*}{$\begin{array}{c}\text { ZTA } \\
\text { (Inferior) }\end{array}$} & 4 & 170 & 13 & 144 & \multirow{3}{*}{$159 \pm 26$} \\
\hline & 5 & 165 & 14 & 154 & \\
\hline & 6 & 175 & 15 & 145 & \\
\hline \multirow{3}{*}{$\begin{array}{l}\text { Metal de solda } \\
\quad \text { (Superior) }\end{array}$} & 7 & 180 & 10 & 168 & \multirow{3}{*}{$178 \pm 11$} \\
\hline & 8 & 183 & 11 & 184 & \\
\hline & 9 & 177 & 12 & 176 & \\
\hline \multirow{3}{*}{$\begin{array}{l}\text { Metal de solda } \\
\quad \text { (Inferior) }\end{array}$} & 7 & 142 & 10 & 146 & \multirow{3}{*}{$144 \pm 12$} \\
\hline & 8 & 138 & 11 & 140 & \\
\hline & 9 & 145 & 12 & 155 & \\
\hline
\end{tabular}

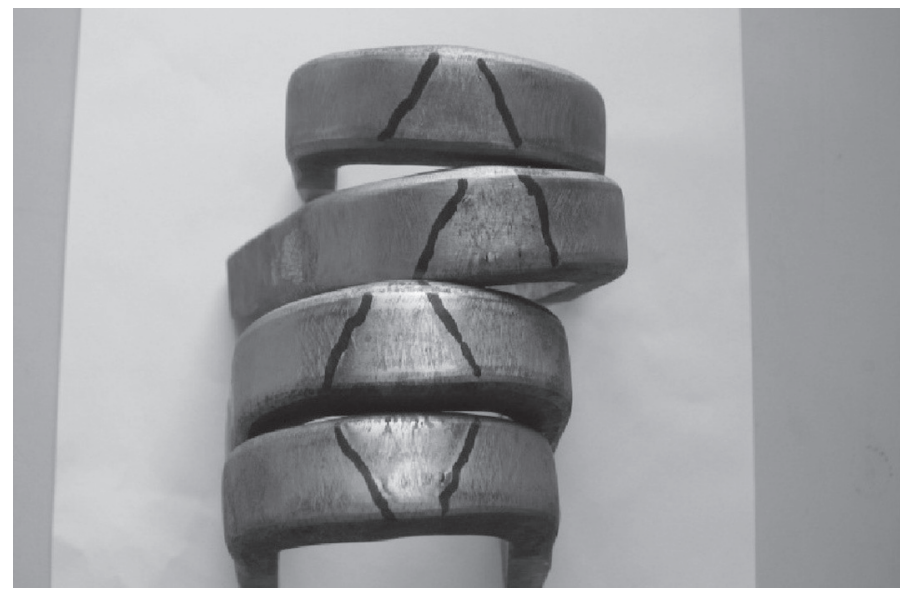

(a)

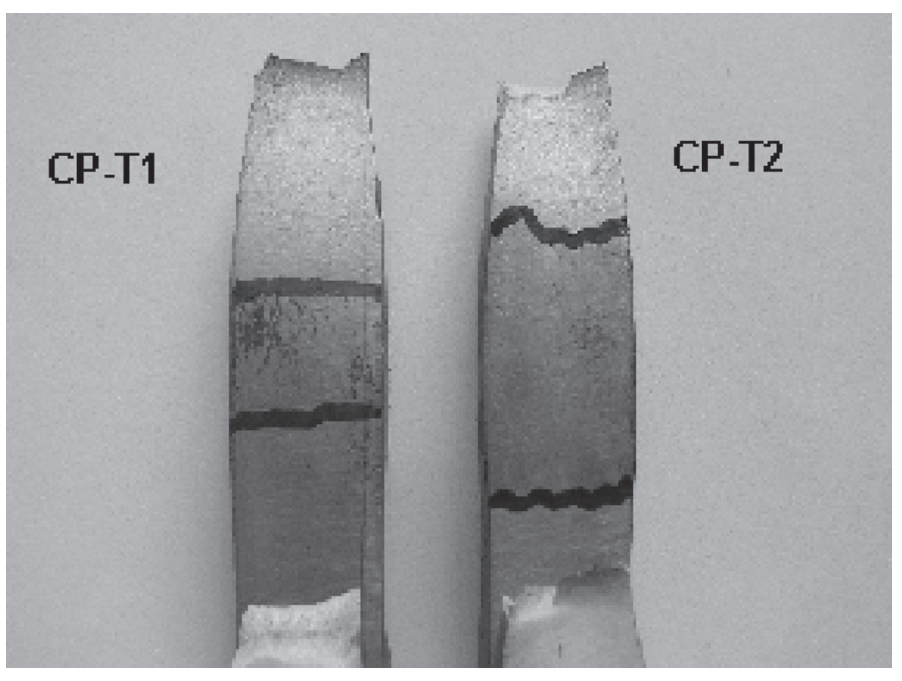

(b)

Figura 11 Resultado dos ensaios de: (a) dobramento e (b) tração

Tabela 5 - Resultados do ensaio de tração.

\begin{tabular}{|c|c|c|c|}
\hline Corpos de prova & $\begin{array}{c}\text { Resistência a Tração. } \\
\text { Aço A-36 (MPa) }\end{array}$ & $\begin{array}{c}\text { Resistência à Tração } \\
\text { Obtida ( MPa) }\end{array}$ & Local de Ruptura \\
\hline CP-T1 & $400-550$ & 432 & Metal Base \\
\hline CP-T2 & $400-550$ & 437 & Metal Base \\
\hline
\end{tabular}




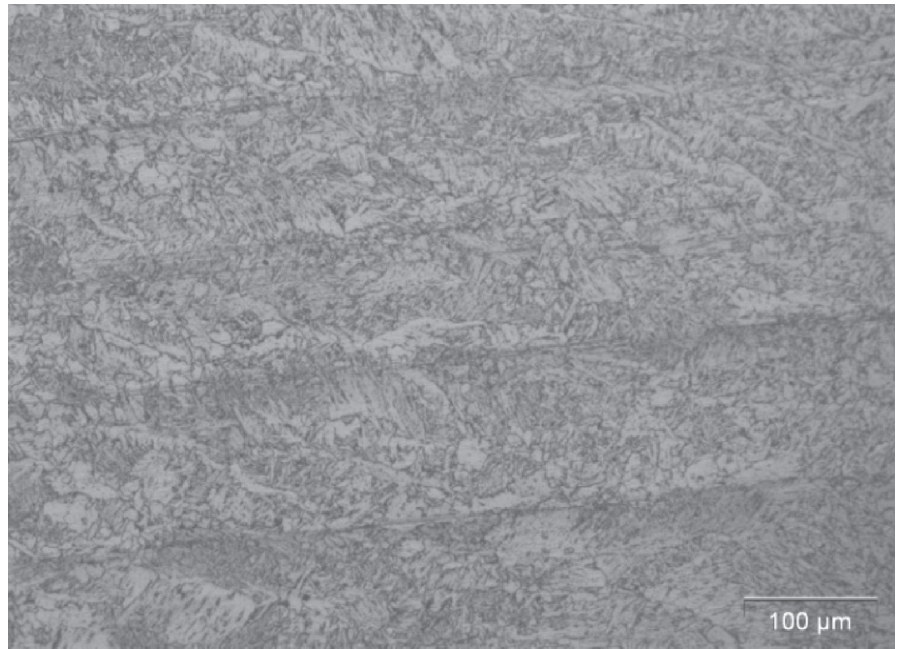

(a)

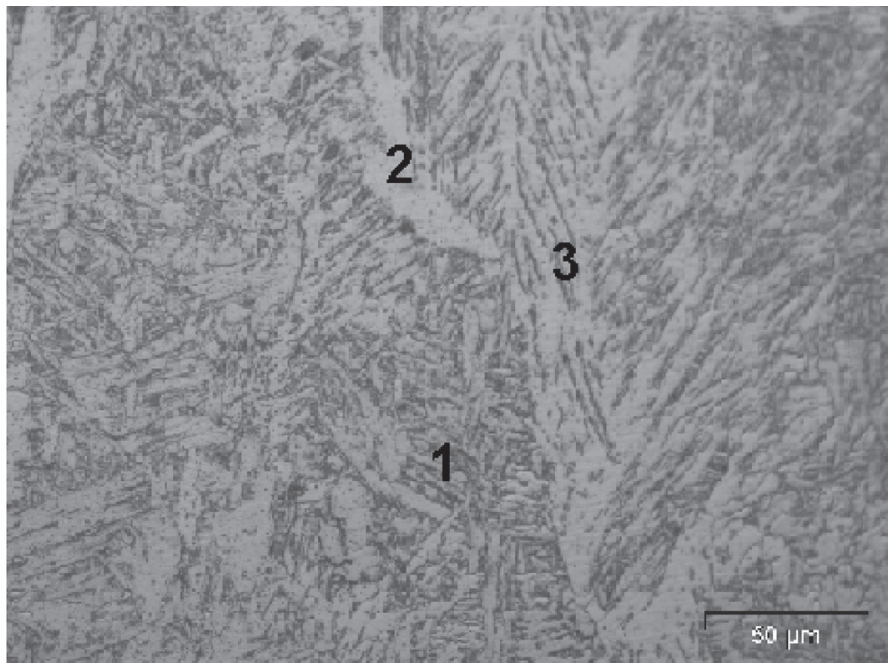

(b)

Figura 12 Micrografia da seção transversal do primeiro passe de solda. (a) aumento de 200X e (b) aumento de 500X. Sendo: 1- AF, 2- $\mathrm{PF}(\mathrm{G})$ e $3-\mathrm{FS}(\mathrm{A})$

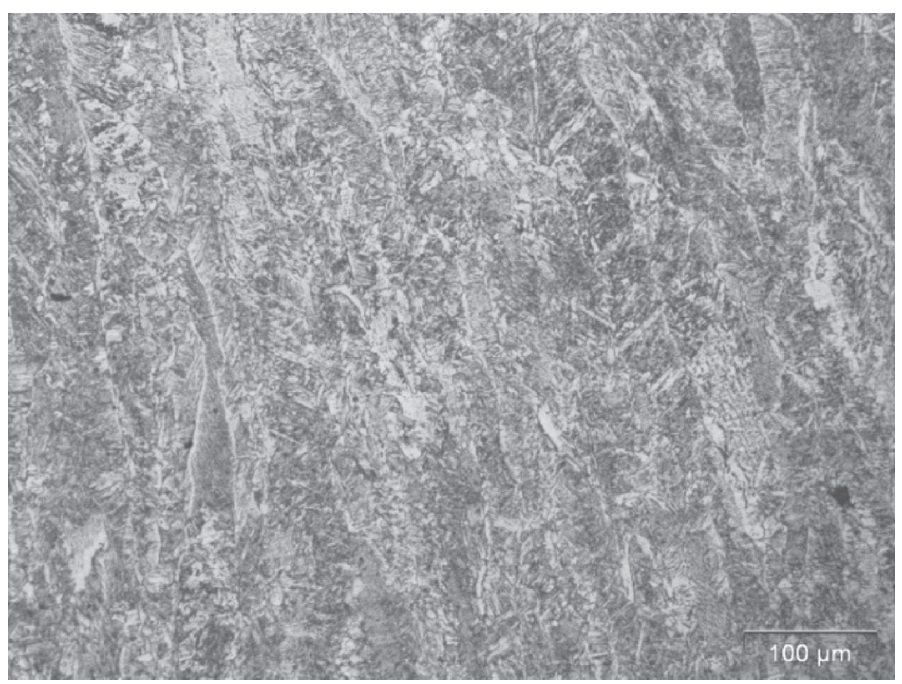

(a)

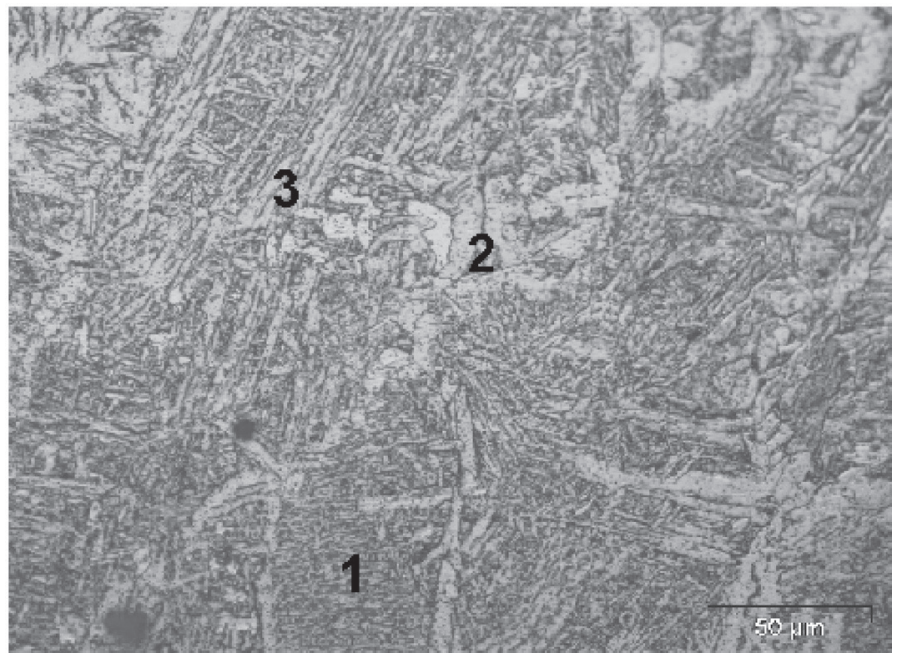

(b)

Figura 13 Micrografia da seção transversal do ultimo passe de solda. (a) aumento de 200X e (b) aumento de 500X. Sendo: 1- AF, 2 $\mathrm{PF}(\mathrm{G})$ e $3-\mathrm{FS}(\mathrm{A})$

solda possuem os mesmos constituintes, apesar de proporções diferentes, o que indica que não houve contaminação do material do suporte cerâmico no cordão de solda. Os resultados do EDS (figuras 15 e 16) mostram que os elementos encontrados na composição da inclusão do passe de raiz não são elementos relacionados com a constituição da cordierita, pois esta é composta de oxido de silício, de magnésio e de alumínio. Para que isto acontecesse o resultado da análise teria que apresentar o elemento magnésio, o que não ocorreu. Já a presença de silício e alumínio é atribuída à oxidação destes elementos químicos na poça de fusão, provenientes do metal de adição e do metal base, particularmente sob a forma de desoxidadantes.

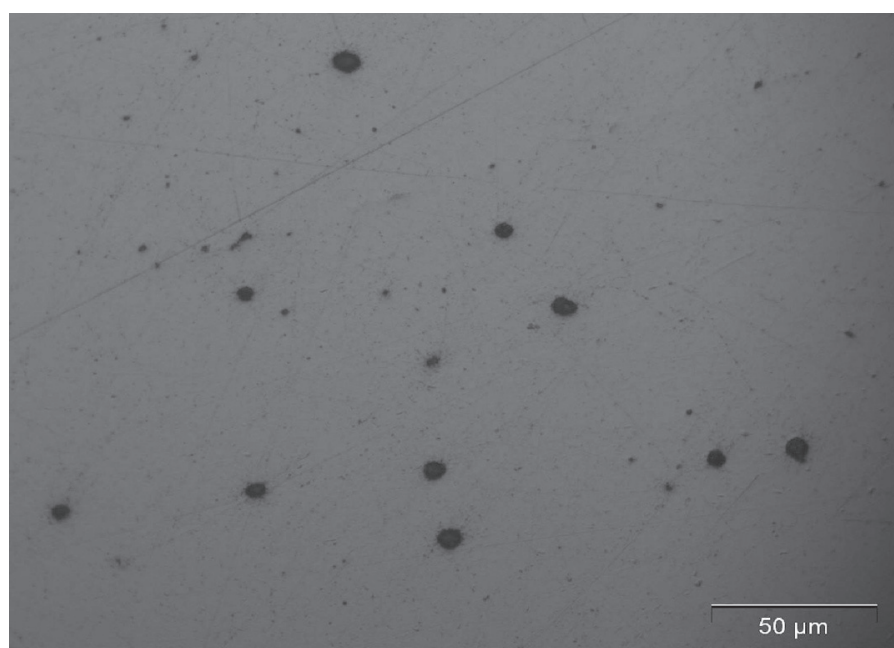

Figura 14 Inclusões no passe de raiz na junta soldada com vários passes. 


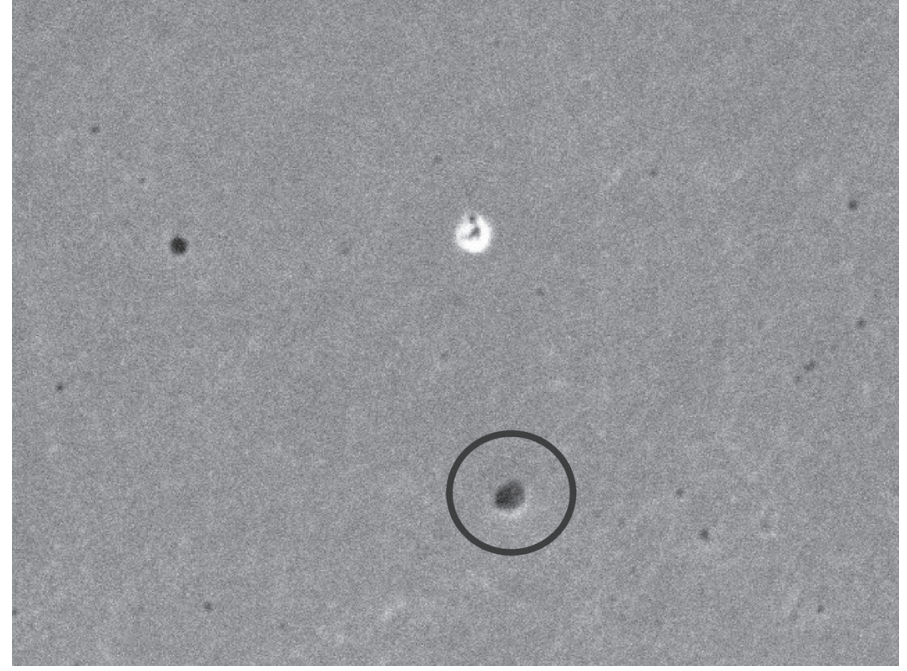

(a)

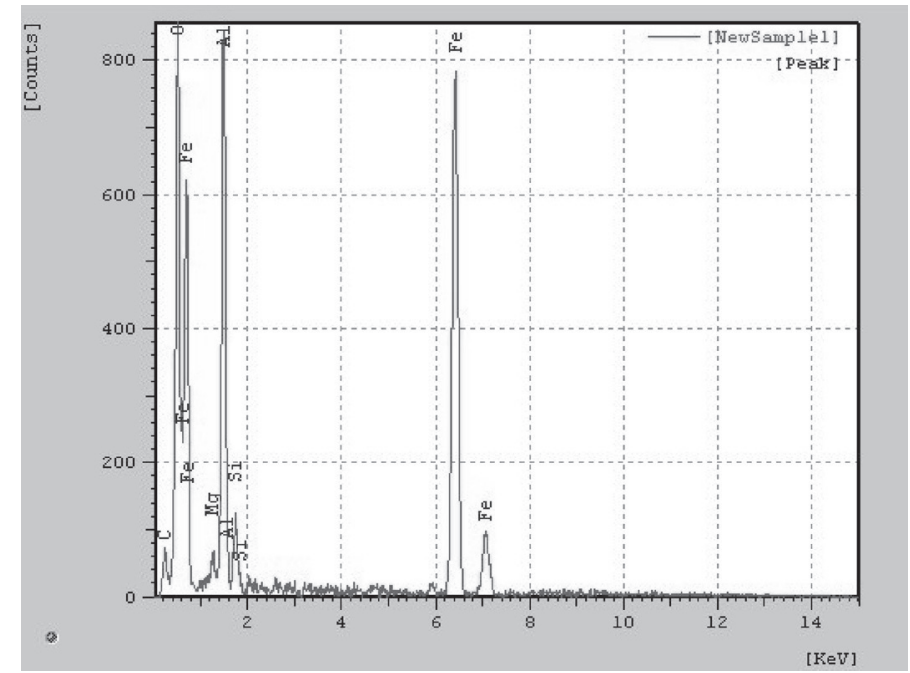

(b)

Figura 15 - Imagem do MEV sem ataque químico e EDS das inclusões no ultimo passe de solda (a) Aumento: 1500X (b) EDS da inclusão selecionada em (a).

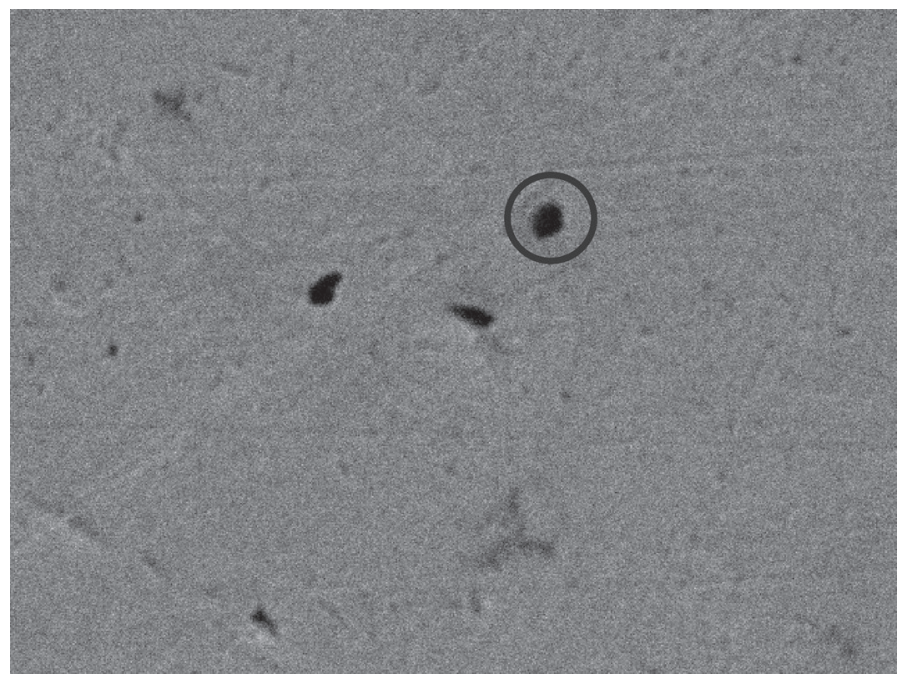

(a)

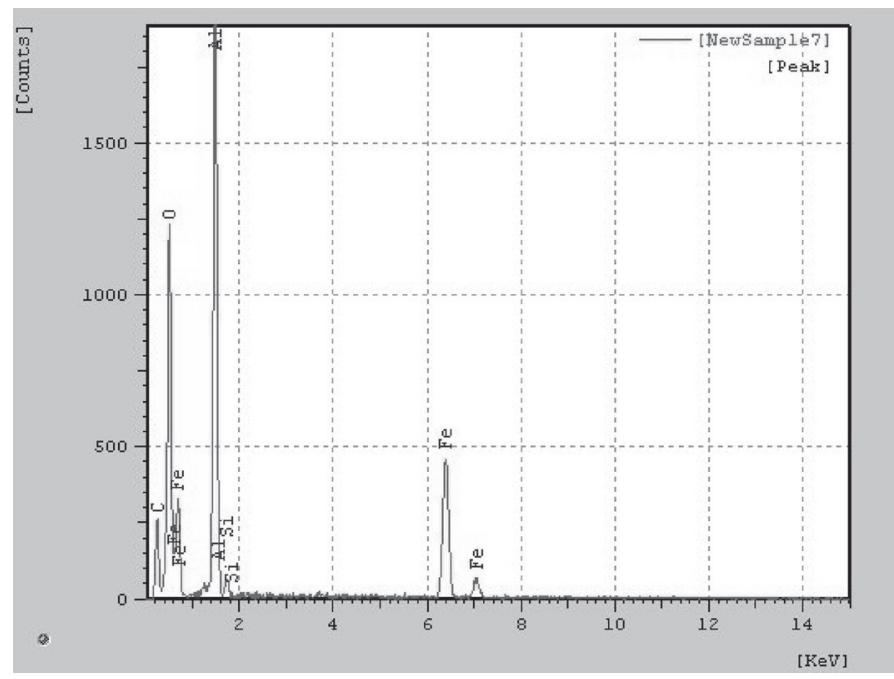

(b)

Figura 16 - Imagem do MEV sem ataque químico e EDS das inclusões no passe de raiz (a) Imagem do MEV sem ataque químico com aumento: 2400X e (b) EDS da inclusão no passe de raiz selecionada em (a)

\section{Conclusões}

Ao avaliar o suporte cerâmico de cordierita produzido em laboratório e avaliado neste trabalho para a soldagem unilateral de aços estruturais pode-se concluir que:

A qualidade da raiz da solda, que esteve em contato com o suporte cerâmico de cordierita, após ensaios não destrutivos apresentou-se isenta de descontinuidades, com bom acabamento do cordão, com penetração nas laterais do chanfro.

Os resultados do ensaio de microdureza Vickers não apresentaram diferenças significativas após a deposição do passe de raiz e na junta soldada com vários passes de solda, mostrando que a técnica de soldagem unilateral com suporte cerâmico de cordierita não interfere na dureza da junta soldada.
Os resultados das propriedades mecânicas da junta soldada (tração e dobramento) com o suporte cerâmico produzido mostraram-se semelhantes aos obtidos com técnicas de soldagem convencionais.

Os constituintes microestruturais no metal de solda do passe de raiz são semelhantes aos do passe de acabamento e condizentes com os observados em aços ferríticos.

Não houve contaminação do material do suporte cerâmico nas inclusões encontradas no passe de raiz.

\section{Agradecimentos}

À FAPERJ, ao CNPq e a SHIMADZU pelo apoio recebido. 


\section{Referências Bibliográficas}

[1] PARANHOS, R. P. R., SOUZA, A. C Soldagem a Arco Submerso. Rio de Janeiro: FIRJAN/SENAI, 87 p., 1999.

[2] Muir, J., Single side panel welding with ceramic tile backing, Metal Construction, p.651-653, October; 1985

[3] MALIN, V., "Root Weld Formation in Modified Refractory Flux One-Sided Welding: part 1 - Effect of Welding Variables, Welding journal, vol. 80 pp. 217s- 226s, e part 2 - Effect of Joint Geometry, Welding Journal, vol. 80 pp. 227s-237s, September, 2001.

[4] ALMEIDA, L.L.P., TATAGIBA, L.C.S., ROCHA, J.P., BASTOS, L.R., RIBEIRO, P.C., PARANHOS, R.P.R. "Avaliação da Junta Soldada com Suporte Cerâmico a Base do Mineral Refratário Cordierita." CD-ROM dos Anais do $5^{\circ}$ COBEFCongresso Brasileiro de Engenharia de Fabricação - Seleção de Soldagem, Belo Horizonte, MG, Brasil, 2009.

[5] ALMEIDA, L.L.P; TATAGIBA, L.C.S., VIEIRA, C.M., RAMALHO, J., PARANHOS, R.P.R. "Estudo de Formulações e das Variáveis de Fabricação de um Suporte de Solda Cerâmico". Soldagem \&Inspeção, vol.14, n.4, p. 288-297, 2009.

[6] ALMEIDA, L.L.P. "Desenvolvimento de Suporte Cerâmico para Aplicação em Soldas Unilaterais com Elevada Produtividade.” Dissertação (Mestrado em Engenharia e Ciências dos Materiais) - Campos dos Goytacazes - RJ, Universidade Estadual do Norte Fluminense Darcy Ribeiro - UENF, 127p., 2009.

[7] ANDRADE, S. T, "Mapeamento do processo mecanizado de Soldagem unilateral FCAW com backing Cerâmico aplicável no passe de raiz em aço Carbono". Belo Horizonte - MG, Universidade Federal de Minas Gerais - UFMG. 103p., 2007. 